SCIENTIFIC REPORT

\title{
Infantile infection and diabetes insipidus in children with optic nerve hypoplasia
}

\author{
S P Donahue, A Lavina, J Najiar
}

Br J Ophthalmol 2005;89:1275-1277. doi: 10.1136/bjo.2005.069609

Background: Bilateral optic nerve hypoplasia (BONH) is often associated with other central nervous system midline abnormalities (septo-optic dysplasia). Hormonal dysfunction, caused by anterior (cortisol) and posterior (ADH) pituitary involvement, can be sudden, severe, and life threatening. Methods: Case series. Three cases of septo-optic dysplasia (SOD) presenting as infantile infection with associated diabetes insipidus are reported. The diagnosis of SOD was suspected only after ophthalmological evaluation; further evaluation led to the diagnosis of panhypopituitarism.

Conclusions: A high index of suspicion is required to diagnose $S O D$ in children when the disorder presents with infantile infection and hypernatraemia. Early warning signs of neonatal jaundice and hypoglycaemia should prompt ophthalmological evaluation.

\footnotetext{
$\mathrm{O}$
} ptic nerve hypoplasia (ONH) is a congenital abnormality of the optic nerve characterised by a small optic disc located within a normal scleral canal. It is often associated with midline central nervous system anomalies such as absence of the septum pellucidum or agenesis of the corpus callosum, and is then called septo-optic dysplasia (de Morsier's syndrome). The associated hypothalamic and pituitary dysfunction can produce hypoglycaemia, hypothyroidism, growth retardation, diabetes insipidus, and a lack of glucocorticoid response to stress, which can be life threatening. ${ }^{1}$ We recently encountered three infants thought to be normal who presented with infantile infection severe enough to warrant hospitalisation. All developed diabetes insipidus, and were later found to have bilateral ONH. Two had history of neonatal jaundice and neonatal hypoglycaemia. We believe that undiagnosed pituitary and endocrine dysfunction contributed to the severity and morbidity of their infections. The presence of jaundice and hypoglycaemia in the neonatal period should prompt ophthalmological evaluation.

\section{CASE 1}

An 11 week old white male was sent to a community hospital by his grandmother after becoming "limp" and "floppy" and sleeping through his feeds. Gestational history was significant for recurrent maternal genital herpes, and alcohol, cocaine and marijuana abuse until the seventh month of pregnancy. The child weighed $6 \mathrm{lb} 7 \mathrm{oz}(2.92 \mathrm{~kg})$ at birth. He experienced hypoglycaemia and jaundice in the neonatal nursery, was treated and released, and appeared normal until presentation.

Upon presentation, the child's heart rate was 50 beats/min, and he was lethargic and hypotonic. His serum sodium was $154 \mathrm{mg} / \mathrm{dl}$, and white blood cell (WBC) count was 17000 . Lumbar puncture revealed $\mathrm{WBC}=14$, red blood cells $(\mathrm{RBC})$ $=295$, protein $=156 \mathrm{mg} / \mathrm{dl}$, glucose $=36 \mathrm{mg} / \mathrm{dl}$, and a normal gram stain. The child was given a presumptive diagnosis of viral meningitis (based upon LP results and normal cerebrospinal fluid (CSF) cultures), but was started on cefotaxime (100 mg/kg/day) and aciclovir $(30 \mathrm{mg} / \mathrm{kg} /$ day $)$. The sodium remained high despite fluid replacement and hypo-osmolar urine output. The child was noted to have unequal pupils, and a non-contrast head computed tomograph (CT) at that institution revealed a hypodense frontal lobe irregularity of unclear aetiology.

The child was then transferred to our institution, where hydration was continued and 1-deamino-8-D-arginine vasopressin (DDAVP) was begun for central diabetes insipidus. Other laboratory abnormalities included anaemia (HCT 26\%), hyperbilirubinaemia $(3.7 \mathrm{mg} / \mathrm{dl})$, and several transient episodes of marginal hypoglycaemia (glucose in lower $60 \mathrm{sec}-$ onds). TORCH titres were negative for acute infection. Thyroid hormone and serum cortisol levels were both low: $\mathrm{TSH}=14.7 \mu \mathrm{U} / \mathrm{ml}, \mathrm{FT} 4=0.5 \mu \mathrm{U} / \mathrm{ml}$; serum cortisol $=1 \mu \mathrm{g} / \mathrm{dl}$. Brain magnetic resonance imaging (MRI) revealed an elongated and tubular fourth ventricle, absent septum pellucidum, small corpus callosum, small optic nerves and chiasm, interdigitation of the gyri in the frontal lobes, and atrophic basal ganglia. The normal posterior pituitary bright spot was absent.

Our evaluation found nystagmus with no aversive response to bright light. The right pupil was $4 \mathrm{~mm}$ and the left was $3 \mathrm{~mm}$, each with minimal reaction. Funduscopic examination revealed small, pale optic nerves bilaterally. Following control of the endocrine problems, the child's condition stabilised, and he was sent home on DDAVP, hydrocortisone, and Synthroid.

\section{CASE 2}

A 5 week old previously healthy girl had a 2 day history of cough, congestion, and fever. Over 24 hours, she became less active and stopped eating. She was admitted to another hospital for a septic examination. Pregnancy was complicated by gestational diabetes but birth was at 35 weeks gestation and she weighed $5 \mathrm{lb} 7 \mathrm{oz}(2.47 \mathrm{~kg})$. There was no neonatal jaundice or hypoglycaemia. The mother denied using valproate, nalidixic acid, or LSD.

Admission laboratory tests showed a WBC count of 2500 with $9 \%$ segmented and $27 \%$ banded cells, and a serum sodium of $156 \mathrm{mg} / \mathrm{dl}$ with hypotonic urine. Initial lumbar puncture revealed numerous Gram positive cocci with a positive group B streptococcal antigen. Cultures of blood and spinal fluid yielded group B streptococcus. The child was placed on ampicillin and gentamicin. The hospital course was complicated by fluctuating sodium levels, which responded to DDAVP. Serum growth hormone and thyroid hormone were low, but a cortisol stimulation test was normal.

At age 8 months, the patient was evaluated and treated elsewhere for large angle esotropia. Two years later, following

Abbreviations: $\mathrm{ACTH}$, adrenocorticotrophic hormone; $\mathrm{BONH}$, bilateral optic nerve hypoplasia; SOD, septo-optic dysplasia 
two strabismus surgeries, the child was referred for ophthalmological examination because of nystagmus and persistent esotropia. Visual acuity was uncentral, unsteady, and unmaintained in both eyes. She had nystagmus and approximately 35 prism dioptres of esotropia. Both optic nerves were small and hypoplastic. The previous ophthalmology notes did not mention abnormal optic nerves, and did not indicate a examination for the nystagmus. Outpatient head MRI revealed encephalomalacia, schizencephaly in the right hemisphere, and an absent posterior pituitary bright spot. A diagnosis of septo-optic dysplasia was made at this time. She was treated with replacement therapy for deficiencies of growth hormone, thyroid hormone, and ADH.

\section{CASE 3}

A $3 \frac{1}{2}$ month old white male presented to an outside hospital with 3 days of cough, congestion, poor oral intake, increased work of breathing, and a fever of $102.4^{\circ} \mathrm{F}$. He was born at 39 weeks gestation to a nulliparous mother. The pregnancy was complicated by severe maternal dehydration secondary to food poisoning and viral gastroenteritis at 6.5 months and 7.5 months gestation respectively. The mother had been treated with antibiotics before delivery for positive cultures of group b streptococcus. Jaundice and hypoglycaemia occurred in the newborn nursery.

Before transfer to our institution, he had been treated for respiratory syncytial virus (RSV) bronchiolitis, and otitis media, and had a serum sodium of $155 \mathrm{mg} / \mathrm{dl}$.

On admission at our institution, temperature was $100.7^{\circ} \mathrm{F}$, respirations $48 / \mathrm{min}$, and pulse $177 / \mathrm{min}$. Pus was visible behind the right tympanic membrane. Nystagmus, unequal pupils, and an exotropia were noted by the admitting service. Sodium reached $162 \mathrm{mg} / \mathrm{dl}$ despite intravenous fluid replacement.

Our examination demonstrated right hemiparesis, right amaurotic pupil, right gaze palsy, left relative afferent pupillary defect, left gaze paretic nystagmus, left ptosis, and an anisocoria consistent with left Horner's syndrome. Dilated fundus examination demonstrated bilateral optic nerve hypoplasia. Given these findings and the persistent hypernatraemia, we suspected septo-optic dysplasia with panhypopituitarism, and recommended urgent paediatric endocrinology consult and neuro-imaging.

MRI showed hypoplastic optic nerves and optic tracts, absent septum pellucidum, bilateral schizencephaly, bilateral cortical dysplasia, an attenuated small hypothalamic stalk, and anterior corpus callosum, and absent pituitary bright spot. The brainstem was remarkably normal. Paediatric endocrinology evaluation confirmed central diabetes insipidus, hypothyroidism, and low serum cortisol $(6.6 \mu \mathrm{g} / \mathrm{dl})$. The patient's status eventually improved and he was discharged.

\section{DISCUSSION}

We report three infants with previously undiagnosed bilateral ONH who presented with infantile infection and hypernatraemia. Two had neonatal jaundice and hypoglycaemia, which is often a harbinger of bilateral $\mathrm{ONH}$ and endocrine anomalies. One patient (case 2) had an intact septum pellucidum, but other abnormalities typically seen with BONH and SOD. In all three cases, the parents had noticed an ocular abnormality in early life. Neuro-imaging found significant midline CNS abnormalities in all three, including absence of the normal posterior pituitary bright spot. In one case, the pituitary images were read as normal until they were reviewed by us. All three children had SOD diagnosed only after our ophthalmological evaluation.

The relation between bilateral $\mathrm{ONH}$ and mid-line CNS abnormalities has been well documented..$^{2-7}$ These midline defects are believed to be caused by an insult during prosencephalic development (gestation week 13) which affects midline structures including the cerebral hemispheres, the hypothalamus, and the pituitary, and produces pituitary and hypothalamic abnormalities. ${ }^{8-11}$ Ectopia or absence of the posterior pituitary bright spot is a very sensitive MRI indicator of anterior pituitary dysfunction, ${ }^{5}{ }^{12}$ and occurred in all three patients. This sign is also a marker for diabetes insipidus in patients with BONH.

In addition to diabetes insipidus, other associated endocrine abnormalities in BONH include adrenocorticotrophic hormone (ACTH) deficiency, ${ }^{12}$ thyroid stimulating hormone deficiency, and growth hormone deficiency. ${ }^{4}$ Cortisol insufficiency often becomes manifest only during periods of stress. Brodsky et al recently reported five children with bilateral $\mathrm{ONH}$ who experienced sudden death during stress, and postulated this to be due to an abnormal cortisol response. ${ }^{1}$ We believe our patients began with mild childhood infectious symptoms that progressed to meningitis because of insufficient endocrine responses to the stress of the infection. Two of our patients had abnormal cortisol response during physiological testing. Low cortisol levels lead to poor counter-regulatory systems causing hypoglycaemia and/or low blood pressure. This, in addition to diabetes insipidus with resultant dehydration and hypernatraemia, can cause significant morbidity. Therefore, it is important that evaluation of the hypothalamic-pituitary-adrenal axis be performed as part of the endocrine examination for patients diagnosed with $\mathrm{BONH}$, or those having unilateral $\mathrm{ONH}$ but neonatal jaundice or hypoglycaemia.

Our cases illustrate how the endocrinological abnormalities seen with OHN can complicate a child's normal response to typical childhood illnesses. SOD should be in the differential diagnosis of any infant with hypotonia, lethargy, or jaundice, who has unexplained hypoglycaemia or hypernatraemia, especially if ocular findings such as nystagmus or poor visual behaviour are present. Prompt ophthalmological and endocrine consultation and MRI imaging are mandatory for establishing the extent of hypothalamic-pituitary axis abnormalities, and minimising morbidity.

\section{Authors' affiliations}

S P Donahue, A Lavina, Department of Ophthalmology and Visual Sciences, Vanderbilt University School of Medicine, Nashville, TN, USA S P Donahue, Department of Neurology, Vanderbilt University School of Medicine, Nashville, TN, USA

J Naijar, S P Donahue, Department of Pediatrics, Vanderbilt University School of Medicine, Nashville, TN, USA

Support: In part by an unrestricted grant from Research to Prevent Blindness (RPB), New York, NY to the Vanderbilt University Department of Ophthalmology. Dr Donahue was the recipient of a Career Development Award from Research to Prevent (RPB), New York, USA.

Correspondence to: Sean P Donahue, MD, PhD, Department of Ophthalmology and Visual Sciences, Vanderbilt University School of Medicine, 8000 Medical Center East, Nashville, TN 37232-8808, USA; sean.donahue@vanderbilt.edu

Accepted for publication 6 June 2005

\section{REFERENCES}

1 Brodsky MC, Conte FA, Taylor D, et al. Sudden death in septo-optic dysplasia. Report of 5 cases. Arch Ophthalmol 1997;115:66-70.

2 Margalith $\mathrm{D}$, Jan JE, McCormick $\mathrm{AQ}$, et al. clinical spectrum of congenital optic nerve hypoplasia: review of 51 patients. Develop Med Child Neurol 1984;26:311-22

3 Zeki SM, Hollman AS, Dutton GN. Neuroradiological features of patients with optic nerve hypoplasia. J Pediart Ophthalmol Strabismus 1992;29:107-12.

4 Siatkowski RM, Sanchez JC, Andrade R, et al. The clinical, neuroradiographic, and endocrinologic profile of patients with bilateral optic nerve hypoplasia. Ophthalmology 1997; 104:493-6. 
5 Brodsky MC, Glasier CM. Optic nerve hypoplasia: clinica significance of associated central nervous system abnormalities on magnetic resonance imaging. Arch Ophthalmol 1993;111: 66-74.

6 Brodsky MC, Glasier CM, Pollock SC, et al. Optic nerve hypoplasia: identification by magnetic resonance imaging. Arch Ophthalmol 1990; 108:1562-7.

7 Brodsky MC. Optic nerve hypoplasia with posterior pituitary ectopia: male predominance and non-association with breech delivery. Am J Ophthalmol 1999:127:238-9.

8 Costin G, Murphree AL. Hypothalamic-pituitary function in children with optic nerve hypoplasia. AJDC 1985;139:249-54.
9 Margalith D, Tze WJ, Jan JE. Congenital optic nerve hypoplasia with hypothalamic-pituitary dysplasia: a review of 16 cases. AJDC 1985;139:361-6.

10 Leaf AA, Ross RJM, Jones RB, et al. Response to growth hormone-releasing hormone as evidence of hypothalamic defect in optic nerve hypoplasia. Acta Pediatr Scand 1989;78:436-9.

11 Sorkin JA, Davis PC, Meacham LR, et al. Optic nerve hypoplasia: absence of posterior pituitary bright signal on magnetic resonance imaging correlates with diabetes insipidus. Am J Ophthalmol 1996;122:717-23.

12 Phillips PH, Spear C, Brodsky MC. Magnetic resonance diagnosis of congenital hypopituitarism in children with optic nerve hypoplasia. J AAPOS $2001 ; 5: 275-80$.

\section{Clinical Evidence - Call for contributors}

Clinical Evidence is a regularly updated evidence-based journal available worldwide both as a paper version and on the internet. Clinical Evidence needs to recruit a number of new contributors. Contributors are healthcare professionals or epidemiologists with experience in evidence-based medicine and the ability to write in a concise and structured way.

Areas for which we are currently seeking authors:

- Child health: nocturnal enuresis

- Eye disorders: bacterial conjunctivitis

- Male health: prostate cancer (metastatic)

- Women's health: pre-menstrual syndrome; pyelonephritis in non-pregnant women

However, we are always looking for others, so do not let this list discourage you.

Being a contributor involves:

- Selecting from a validated, screened search (performed by in-house Information Specialists) epidemiologically sound studies for inclusion.

- Documenting your decisions about which studies to include on an inclusion and exclusion form, which we keep on file.

- Writing the text to a highly structured template (about 1500-3000 words), using evidence from the final studies chosen, within 8-10 weeks of receiving the literature search.

- Working with Clinical Evidence editors to ensure that the final text meets epidemiological and style standards.

- Updating the text every six months using any new, sound evidence that becomes available. The Clinical Evidence in-house team will conduct the searches for contributors; your task is simply to filter out high quality studies and incorporate them in the existing text.

- To expand the topic to include a new question about once every 12-18 months.

If you would like to become a contributor for Clinical Evidence or require more information about what this involves please send your contact details and a copy of your CV, clearly stating the clinical area you are interested in, to Klara Brunnhuber (kbrunnhuber@ bmigroup.com).

\section{Call for peer reviewers}

Clinical Evidence also needs to recruit a number of new peer reviewers specifically with an interest in the clinical areas stated above, and also others related to general practice. Peer reviewers are healthcare professionals or epidemiologists with experience in evidence-based medicine. As a peer reviewer you would be asked for your views on the clinical relevance, validity, and accessibility of specific topics within the journal, and their usefulness to the intended audience (international generalists and healthcare professionals, possibly with limited statistical knowledge). Topics are usually 1500-3000 words in length and we would ask you to review between 2-5 topics per year. The peer review process takes place throughout the year, and our turnaround time for each review is ideally 10-14 days.

If you are interested in becoming a peer reviewer for Clinical Evidence, please complete the peer review questionnaire at www.clinicalevidence.com or contact Klara Brunnhuber (kbrunnhuber@bmigroup.com). 